\title{
Differences in Pornography Use Among Couples: Associations with Satisfaction, Stability, and Relationship Processes
}

\author{
Brian J. Willoughby \\ Brigham Young University - Provo \\ Jason S. Carroll \\ Brigham Young University - Provo, jcarroll@byu.edu \\ Dean M. Busby \\ Brigham Young University - Provo \\ Cameron C. Brown \\ Brigham Young University - Provo \\ Follow this and additional works at: https://scholarsarchive.byu.edu/facpub \\ Part of the Other Social and Behavioral Sciences Commons
}

\section{Original Publication Citation}

Willoughby, B. J., Carroll, J. S., Busby, D. M., \& Brown, C.* (2016). Differences in Pornography Use Among Couples: Associations with Satisfaction, Stability, and Relationship Processes. Archives of Sexual Behavior, 45, 145-158.

\section{BYU ScholarsArchive Citation}

Willoughby, Brian J.; Carroll, Jason S.; Busby, Dean M.; and Brown, Cameron C., "Differences in Pornography Use Among Couples: Associations with Satisfaction, Stability, and Relationship Processes" (2015). Faculty Publications. 4364.

https://scholarsarchive. byu.edu/facpub/4364

This Peer-Reviewed Article is brought to you for free and open access by BYU ScholarsArchive. It has been accepted for inclusion in Faculty Publications by an authorized administrator of BYU ScholarsArchive. For more information, please contact ellen_amatangelo@byu.edu. 


\title{
Differences in Pornography Use Among Couples: Associations with Satisfaction, Stability, and Relationship Processes
}

\author{
Brian J. Willoughby ${ }^{1} \cdot$ Jason S. Carroll $^{1} \cdot$ Dean M. Busby ${ }^{1} \cdot$ Cameron C. Brown $^{1}$
}

Received: 23 August 2013 / Revised: 21 March 2014 / Accepted: 8 March 2015 / Published online: 31 July 2015

(C) Springer Science+Business Media New York 2015

\begin{abstract}
The present study utilized a sample of 1755 adult couples in heterosexual romantic relationships to examine how different patterns of pornography use between romantic partners may be associated with relationship outcomes. While pornography use has been generally associated with some negative and some positive couple outcomes, no study has yetexplored how differences between partners may uniquely be associated with relationship well-being. Results suggested that greater discrepancies between partners in pornography use were related to less relationship satisfaction, less stability, less positive communication, and more relational aggression. Mediation analyses suggested that greater pornography use discrepancies were primarily associated with elevated levels of male relational aggression, lower female sexual desire, and less positive communication for both partners which then predicted lower relational satisfaction and stability for both partners. Results generally suggest that discrepancies in pornography use at the couple level are related to negative couple outcomes. Specifically, pornography differences may alter specific couple interaction processes which, in turn, may influence relationship satisfaction and stability. Implications for scholars and clinicians interested in how pornography use is associated with couple process are discussed.
\end{abstract}

Keywords Pornography $\cdot$ Marriage $\cdot$ Sexuality $\cdot$ Sexual desire

\section{Introduction}

Pornography has become a normative and accepted part of our modern culture, particularly in societies where online media is easily accessible (Carroll et al., 2008; Maddox, Rhoades, \&

Brian J. Willoughby

brian.willoughby@byu.edu

1 School of Family Life, Brigham Young University, 2081 JFSB, Provo, UT 84602, USA
Markman, 2009; Olmstead, Negash, Pasley, \& Fincham, 2013). As normative pornography use increases, scholars have sought to understand the effect of pornography use on partners in romantic relationships. In a relationship context, several studies have suggested that pornography use is related to couple outcomes such as less sexual satisfaction, more negative communication, and less relationship satisfaction (Bridges \& Morokoff, 2011; Maddox et al., 2009; Poulsen, Busby, \& Galovan, 2013; Yucel \& Gassanov, 2010). While these studies suggest that pornography use is generally associated with couple outcomes, this scholarship has several important limitations that are important to address as we seek to more fully understand how pornography is associated with sexual relations and couple dynamics.

In the present study, we sought to expand this body of scholarship by addressing a key limitation in the pornography literature on romantic couples. While studies have begun to suggest associations between pornography use and couple outcomes, no study has examined how differences or discrepancies in partners' levels of pornography use may be associated with couple outcomes. Within the present study, we sought to explore how such differences may be associated with outcomes among adult romantic couples, including overall satisfaction and stability, as well as positive communication, relational aggression, and sexual desire.

\section{Individual and Relational Correlates of Pornography Use}

While research is far from conclusive, several studies have now documented that pornography use, especially habitual use or early exposure to pornography, is associated with several individual outcomes. At the individual level, higher rates of pornography use have been found to be associated with greater levels of depression among men (Bridges \& Morokoff, 2011), more negative feelings about romantic partners (Grov, Gillespie, Royce, \& Lever, 2011), and engagement in risky sexual behaviors (Sinkovic, 
Stulhofer, \& Bozic, 2012). This research is partially countered by research which has suggested that pornography exposure may be related to increased sexual knowledge and openness for some individuals (Lofgren-Mårtenson \& Månsson, 2010; Weinberg, Williams, Kleiner, \& Irizarry, 2010).

Regardless of the positive or negative individual effects of pornography consumption, researchers have suggested that the relationship between pornography use and outcomes at the couple level may also be both positive and negative. Like individuallevel results, some research on couples has shown pornography use to have positive correlates. Grov et al. (2011) found that when viewed together as partners, pornography use was associated with increases in sexual frequency, a willingness to try new sexual behaviors, and less boredom with sex. Couples who utilized pornography together also found it easier to discuss sexual wants and fantasies with their partners (Daneback, Traeen, \& Månsson, 2009). Conversely, pornography use appears to be associated with less commitment to one's romantic partner (Bridges \& Morokoff, 2011; Lambert, Negash, Stillman, Olmstead, \& Fincham, 2012), and other scholars have found that pornography use has a negative association with sexual satisfaction within a relationship (Maddox et al., 2009; Yucel \& Gassanov, 2010). Explanations for such negative findings are often connected to script theory (Gagnon \& Simon, 1973). As an individual views the depiction of what are often extraordinary and non-normative sexual situations, that individual's expectations and sexual scripts may begin to alter, providing more opportunities to become dissatisfied with a current sexual partner or sexual activity. According to script theory, pornography would be linked to eventual negative couple outcomes by altering individual sexual scripts and perhaps fostering unrealistic expectations of sexual partners.

A review of existing pornography studies raises the question of why such divergent positive and negative correlates of pornography use would be found at both the individual and couple level. At the individual level, these difference are likely attributable to varying personal acceptance rates of pornography (Nelson, PadillaWalker, \& Carroll, 2010). Individuals who approve of pornography likely escape the negative outcomes that often accompany the cognitive dissonance created when an individual's behaviors contradict their values. At the level of the couple, several studies have hinted at the fact that couple outcomes are influenced by the pornography consumption pattern within the couple in ways that may not be apparent when only examining the individual patterns of each partner. Yucel and Gassanov (2010) noted that their finding linking pornography use to less sexual satisfaction was only found among couples where only one partner utilized pornography. New qualitative research has also suggested that when female partners are allowed to "gate keep" their male partner's pornography use, their relationships do not suffer adverse outcomes (Olmstead et al., 2013). While such findings are useful and speak to the importance of examining within couple differences in pornography use patterns, no study has yet examined how varying levels of discrepancies between partners may provide a more complete picture of how pornography use operates within romantic couples.

Currently, most studies which have explored couple-level differences in pornography use have utilized group comparisons (see Bridges, Bergner, \& Hesson-McInnis, 2003; Grov et al., 2011; Maddox et al., 2009). While these studies have provided valuable insights into how pornography use may influence couple-level dynamics and outcomes, such an approach also diminishes scholars' ability to explore continuous and incremental variation within couples in terms of their couple use patterns. In the present study, we first explored how continuous pornography use discrepancies were associated with the couple-level outcomes of relationship satisfaction, stability, positive communication, and relational aggression. We included relational aggression, defined as negative relational tactics that undermine one's feelings of social connection or acceptance, as it has emerged as an important indicator of unhealthy relationship dynamics (Carroll et al., 2010). Although our data are cross-sectional, we utilized script theory as a conceptual guide to sequence variables across various analytic models. Given that a variety of studies have suggested that general pornography use is related to negative relational outcomes (Bridges et al., 2003; Cooper, Galbreath, \& Becker, 2004; Simmons, Lehmann, \& Collier-Tenison, 2008; Twohig, Crosby, \& Cox, 2009), and group comparison studies also suggest negative outcomes when couples have different usage rates (Grov et al., 2011; Maddox et al., 2009; Olmstead et al., 2013), we propose the following hypotheses:

Hypothesis 1 Couples who report higher discrepancies in pornography use will also report lower relationship satisfaction, less relationship stability, less positive communication, and more relational aggression.

As some studies have suggested that the effect of pornography use on individual and couple well-being may be moderated by the acceptance of pornography (Nelson et al., 2010), we explored such moderation by examining if associations between pornography use discrepancies and relational outcomes were moderated by acceptance of pornography by both partners. Given past research that has suggested that those who approve of or accept pornography may report fewer negative outcomes associated with such use, we propose the following second hypothesis:

Hypothesis 2 Pornography acceptance will moderate the relationship between pornography use discrepancies and relational outcomes in that such associations will only be present when individuals within the couple disapprove of pornography.

To further explore the nature of these associations, we next attempted to examine possible mediating pathways between pornography use discrepancies and general assessments of relational well-being (satisfaction and stability). Relationship research has suggested that both positive communication (Gottman, Coan, Carrere, \& Swanson, 1998) and relational aggression (Carroll et al., 2010) are strong predictors of relationship satisfaction 
and stability. Again drawing on script theory, if pornography influences sexual scripts, such changes may lead to differing relationship expectations for partners and then influence how they behave and interact with each other. Thus, pornography use differences may not have a strong association directly on couple well-being but may have a more pronounced indirect association through varying couple dynamics. Therefore, we explored in mediation models if the associations between relational wellbeing (satisfaction and stability) and pornography use discrepancies were mediated by couple dynamic factors (communication and relational aggression). In line with scripting theory, we also tested an additional mediation model to examine if the desire for sexual frequency mediated relationships between pornography use discrepancies and relational well-being. Some studies have suggested that pornography use may decrease sexual interest among romantic partners (Grov et al., 2011; Lambert et al., 2012; Yucel \& Gassanov, 2010) leading us to the following hypothesis:

Hypothesis 3 Desired sexual frequency, positive communication, and relational aggression will mediate the relationship between couple pornography use discrepancies and relationship satisfaction and stability.

Finally, as gender differences have been remarkably striking in the pornography literature (Carroll et al., 2008; Grov et al., 2011; Maddox et al., 2009; Olmstead et al., 2013; Stack, Wasserman, \& Kern, 2004; Traeen, Spitznogle, \& Beverfjord, 2004; Wetterneck, Burgess, Short, Smith, \& Cervantes, 2012), the gendered dynamics of the associations between pornography use discrepancies and relational outcomes were also of interest. Given previous research that has suggested pornography use may decrease female partner sexual desire (Grov et al., 2011; Schneider, 2000; Yucel \& Gassanov, 2010) and increase male negative relationship processes (Cooper et al., 2004), we proposed the following hypothesis:

Hypothesis 4 Discrepancies in couple pornography use will be associated with less female sexual desire, less male positive communication, and more male relational aggression.

\section{Method}

\section{Participants}

Participants for this study included 3510 individuals who formed 1755 unique mixed-sex couple pairs. These couples were sampled across the United States and formed couple pairs who took the Relationship Evaluation Questionnaire instrument online from 2008 until 2013 (RELATE; see below) (Busby, Holman, \& Taniguchi, 2001). The largest racial group was White (male: $68 \%$; female: $68 \%$ ) followed by Black (male: $4 \%$; female: $3 \%$ ), Asian (male: $4 \%$; female: $5 \%$ ), and Latino (male: $3 \%$; female: $3 \%$ ) participants. The largest religious denomination within the sample was Protestant (male: $33 \%$; female: $34 \%$ ). About a quarter of men $(24 \%)$ and $40 \%$ of females reported a yearly personal income of less than $\$ 20,000$, while $12 \%$ of men and $4 \%$ of women within the sample reported a personal yearly income of more than $\$ 140,000$. Fifty three percent of male participants had completed some form of post-secondary degree while $54 \%$ of females had obtained such a degree. The average age of the sample was 28.8 years $(S D=8.76)$ for males and 27.0 years $(S D=7.99)$ for females. Most couples were dating (53\%) with $27 \%$ cohabiting and $20 \%$ married. Among married couples, $56 \%$ of the sample had been married for 5 years or more. Among cohabiting and dating couples, $57 \%$ had been together for less than 2 years.

\section{Procedure}

All participants completed an appropriate consent form prior to the completion of the RELATE instrument and all data collection procedures were approved by the institutional review board at the authors' university. Individuals completed RELATE online after being exposed to the instrument through a variety of settings. The RELATE assessment is a couple assessment designed to assess and provide feedback to those in romantic relationships. After taking the RELATE, couples are provided with feedback on their relationship strengths and weaknesses that they can utilize either on their own or in conjunction with a third party (e.g., religious leader, clinician). Some participants were referred to the online site by their instructor in a university class, others by a relationship educator or therapist, and some participants found the instrument by searching for it on the web. Participants were instructed to complete the assessment alone and to not discuss their responses with their partner. We refer the reader specifically to Busby et al.'s (2001) discussion of the RELATE for detailed information regarding the theory underlying the instrument and its psychometric properties. Due to the nature of data collection, couples in the present sample tended to be more educated and have healthier relationships when compared to a truly representative national sample.

\section{Measures}

\section{Controls}

Several variables were utilized as control variables given their previous associations with both sexuality and relationship outcomes. For example, previous research has suggested that sexuality within relationships varies by both race (Dariotis, Sifakis, Pleck, Astone, \& Sonenstein, 2011) and socioeconomic factors (Owen, Rhoades, Stanley, \& Fincham, 2010). For the current study, the total education of the couple was also calculated and used as a control. This was based on one item asking each participant the farthest educational milestone they had achieved. Responses ranged from 1 (less than high school) to 9(graduate orprofessional 
degree completed). The responses from both partners were summed to create a composite education score. Relationship length was assessed by one item asking each participant: "How long have you and your partner been married/dating?" Responses ranged from $1(0-3$ months) to 11 (more than 40 years). The participants were also asked for the number of previous divorces (male: $M=$ $0.90, S D=0.56$; female: $M=0.82, S D=0.49)$ and the number of children they had with their partner $(M=0.39, S D=0.96)$. Income was assessed by one item that asked participants to indicate their current yearly gross income before taxes and deductions. Response ranged from 0 (none) to $9(\$ 160,000$ and above). To additionally capture the continuous effect of overall religiosity, a total couple religiosity score was created by summing both male and female scores on a religious attendance item. This item asked each participant how often they attended religious services. Responses ranged from 0 (weekly) to 4 (never).

Some of these demographic controls also focused on couple heterogeneity given previous research which has indicated that couples who have differing demographics or backgrounds may be more prone to negative relational dynamics and outcomes (Heaton, 2002; Teachman, 2002). Such research has suggested that for some background factors it is the differences between couples and not the static factor itself that is linked to relational well-being. These studies have often utilized dichotomous difference variables (measuring any difference) to capture heterogeneity within romantic couples, a strategy also employed in the current study. Specifically, age, race, and religious attendance were identified as three factors where previously research has suggested the importance of couple heterogeneity. Age differences between partners were calculated by subtracting male partner age from female partner age. This variable was recoded so that couples that had more than a 2 year age difference were coded as 1 and all other couples were coded with 0 . Thirty eight percent of couples had an age difference of more than 2 years. Religious differences between couples were based on the one item asking each participant how often they attended religious services. A difference score was calculated by again subtracting male attendance by female attendance. As we were interested in controlling for any religious attendance difference, couples who had any difference in religious attendance were coded with a 1 while couples with congruent attendance were coded with a 0 . Forty three percent of couples had a religious attendance difference. Racial differences were also calculated. Couples who indicated differing racial designations were coded with a 1 while all other couples were coded with 0 .

\section{Couple Sexuality}

Pornography use was assessed by one item asked of each participant: "During the last 12 months, on how many days did you view or read pornography (i.e., movies, magazines, internet sites, adult romance novels)?" Responses ranged from 0 (none) to 5 (almost every day). Pornography use differences were created by subtracting the male partner's response on the use item with their female partner's response on the pornography use item. Responses for this item ranged from -5 to 5 . Positive numbers indicated that the male partner used pornography more than the female partner while negative numbers indicated the opposite. As we were interested in the current study with the general degree of difference/similarity and not the difference based solely on gender, the absolute value of the difference score was computed. While disagreement still exists within the field on the best measure of couple similarity, absolute values scores are still generally considered one of the best assessments of overall couple difference (Luo et al., 2008). Additionally, with couple pornography use differences, very few couples $(5.8 \%)$ reported that female use was higher than male use, creating non-normality with the original variable. The use discrepancy variable ranged from 0 to $5(M=1.23, S D=1.22)$ with a higher number indicating more couple differences in pornography use. A measurement of 0 indicated that both partners matched in their pornography use rate.

One of the weaknesses of using absolute value differences is the uncertainty regarding if actual effects are due to the differences between partners or the individual use patterns used to construct the difference score. In order to control for the baseline pornography use across the couple partnership and explore the unique contribution of the difference score, a control variable was created that summed each partner's individual response on the pornography use item. While the original scores for both male and female use could be used as separate control variables, these variables were directly used to create the discrepancy scores and therefore would create multicollinearity problems within the model. A combined score still captures the overall influence but does not produce problematic results by introducing necessary variance between the discrepancy score and the combined score. While this does not allow for the specific investigation of male or female pornography use independently predicting couple-level outcomes, it does increase the confidence that difference scores are producing significant results independent of baseline measurements. Previous studies have utilized a similar strategy to examine if discrepancy scores have unique contributions once baseline assessments are controlled for (Busby, Holman, \& Neihuis, 2009; Willoughby, Farero, \& Busby, 2014). Once computed, scores on total use ranged from 0 to $9(M=1.95, S D=1.74)$.

Pornography acceptance and sexual desire for both partners was also assessed. Pornography acceptance was measured by averaging six items assessing one's overall acceptance of pornography use individually and as a couple. Items were assessed on an overallagreement scale $(1=$ stronglydisagree $; 5=$ stronglyagree $)$. Sample items included: "Viewing pornography is an acceptable way for single adults to express their sexuality," "Pornography objectifies and degrades women (reverse coded)," and "Pornography is a form of marital infidelity (reverse coded)." Reliability for this scale was in the acceptable range (male: $\alpha=0.91$; female: $\alpha=0.92$ ) and higher scores indicated more acceptance of pornog- 
raphy. Male and female partner scores were combined to form a measure of couple pornography acceptance. Sexual desire was measured by one item which asked "How often do you desire to have sexual intercourse with your partner?" Responses ranged from 0 (never) to 6 (more than once a day).

\section{Couple Outcomes}

Four measures of couple outcomes were used to assess individual satisfaction with the relationship, individual perception of the stability of the relationship, relational aggression, and positive couple communication. Couple scores were created by summing male and female partner scores on each item. Relationship satisfaction was assessed with seven items asking participants how satisfied they were with various aspects of their relationship (e.g., in their sexual relationships and with the overall relationship). Items were rated on a 5 -point scale $(1=$ very dissatisfied to $5=$ very satisfied). Cronbach's alpha was in the acceptable range (male: $\alpha=0.87$; female: $\alpha=0.88$ ). Couples generally reported high satisfaction levels $(M=3.99, S D=0.71)$. The RELATE satisfaction measures employed in this study have shown high test-retest reliability (between 0.76 and 0.78 ) and validity data have consistently shown that this scale is highly correlated with an existing relationship satisfaction and quality scale (Revised Dyadic Adjustment Scale) in both cross-sectional and longitudinal research (Busby et al., 2001, 2009).

Relationship stability was assessed by averaging three items, which asked participants how often the following three things had happened in their relationship: "How often have you thought your relationship (or marriage) might be in trouble?", "How often have you and your partner discussed ending your relationship (or marriage)?", and "How often have you broken up or separated and then gotten back together?"Responses ranged from 1 (never) to 5 (veryoften). These items were reverse coded so that higher scores indicated more stability. Similar to scores on satisfaction, couples within the dataset generally reported high stability levels $(M=4.15, S D=0.70)$. These items were adapted from earlier work by Booth, Johnson, and Edwards (1983). Cronbach's alpha was in the acceptable range (male: $\alpha=0.79$; female: $\alpha=0.80$ ). Previous studies have shown this scale to have test-retest reliability values between 0.78 and 0.86 , to be appropriately correlated with other relationship quality measures, and to be valid for use in cross-sectional and longitudinal research (Busby et al., 2001, 2009; Busby, Ivey, Harris, \& Ates, 2007).

Relational aggression was assessed with seven items adopted from the Couples Relational Aggression and Victimization Scale (CRAViS) (Carroll et al., 2010). Responses were on a five point scale asking participants to relate how often various statements defined their own behavior in their relationship $(1=$ never, $5=$ very often). Sample items included: "I have given my partner the silent treatment or 'cold shoulder' when he/she has hurt my feelings or made me angry in some way" and "I have spread rumors or negative information about my partner to be mean."Scores were averaged across the seven items and higher scores indicated more relational aggression. The scale demonstrated good reliability (males: $\alpha=0.74$ females: $\alpha=0.76$ ).

Positive communication was assessed by asking participants eight items relating to their overall communication patterns. Sample items included: "I am able to listen to my partner in an understanding way," "When I talk to my partner I can say what I want in a clear manner," and "I sit down with my partner and just talk things over." Responses were measured on a 5-point scale $(1=$ never to $5=$ very often $)$. In terms of test-retest and validity information on this scale, the communication items have been shown to have test-retest values between 0.70 and 0.83 and were appropriately correlated with a version of a commonly used Relationship Quality measure as predicted (Busby et al., 2001). Also, this scale has been shown in longitudinal research to be predictive of couple outcomes and are amenable to change in couple intervention studies that focus on communication (Busby et al., 2007). Cronbach's alpha was again in the acceptable range (male: $\alpha=0.89$; female: $\alpha=0.90$ ).

\section{Data Analysis}

In order to explore our initial hypotheses, four couple-level hierarchical regression models (one for each outcome) were first explored using three-step models. The first stepincluded the pornography use difference scores to examine if such differences had simple bivariate associations with relational outcomes. The second step included the addition of all demographic and other couple-level controls (racial difference, age difference, religious difference, relational length, total education, total religiosity, relational length, number of children, number of divorces [both partners], and relationship status) to see if associations with pornography use difference scores held once controls were accounted for. Finally, the third step introduced both the baseline pornography use scores of the couple as well as each partner's sexual desire. This step was included to examine if pornography use differences were uniquely associated with outcomes once baseline couple and individual sexuality variables were included. Interactions between pornography use differences and male/female partner pornography acceptance were then included into final regression models to test if the associations between pornography differences and outcomes were moderated by acceptance levels of either partner. When significant, such interactions were further examined utilizing simple slope analyses (Aiken \& West, 1991). All data were assumed to be missing at random. Little missing data existed for the variables under study $(<2 \%)$. Due to the near absence of missing data, list wise deletion was utilized in all regression models.

In order to test the mediation effect of couple dynamics (positive communication, relational aggression and sexual desire) on the relationship between pornography differences and relational 
outcomes, three structural equation models were established and tested using Mplus version 7 software. As we had data from both partners, actor-partner models (Cook \& Kenny, 2005) were utilized to predict the mediation of both male and female reports of individual relational process on the association between couple pornography use differences and the perception of couple outcomes from both partners. Missing data for SEM analyses utilized full maximum-likelihood estimators.

\section{Results}

\section{Descriptive Results}

Table 1 summarizes bivariate correlations among study variables. Across the sample, males $(M=1.51, S D=1.37)$ reported significantly more pornography use than their female partners $(M=0.44, S D=0.74), t(2485)=38.96, p<.001$. Twenty five percent of all male partners reported at least weekly pornography use while only $2.6 \%$ of female partners reported weekly use. Overall, $70.5 \%$ of male partners reported some pornography use in the last year compared to only $33.7 \%$ of female partners. Male partners $(M=3.00, S D=1.05)$ were also significantly more likely to accept pornography than their female partners $(M=2.73, S D=1.06) t(2463)=16.47, p<.001$.

Examining couple-level differences, only $5.8 \%$ of couples included a female partner who indicated more pornography use than her male partner. Thirty five percent of couples reported equal pornography use. This included $5.8 \%$ of couples where both partners reported no pornography use. Results for pornography acceptance suggested that only $30.7 \%$ of couples were categorized by a female partner who was more accepting of pornography than her male partner. Fourteen percent of the sample included couples who had an identical acceptance of pornography.

\section{Predicting Couple Outcomes}

Hierarchical regression models with three steps were conducted (Step 1: use/acceptance differences; Step 2: controls; Step 3: sexual dynamics and behavior) predicting each of the four relationship outcomes. Given that pornography acceptance may alter the effect of pornography use on couple outcomes, total couple acceptance was originally included in the final step of regression models as an additional control. However, it was found that total pornography use and acceptance scores heavily overlapped $(r=.57, p<.001)$ creating multicollinearity problems in the model. For this reason, total acceptance was dropped from the model and total pornography use was retained to achieve unbiased results. The inclusion of total acceptance did not change any of the significant results for couple pornography use differences. Preliminary models testing male and female

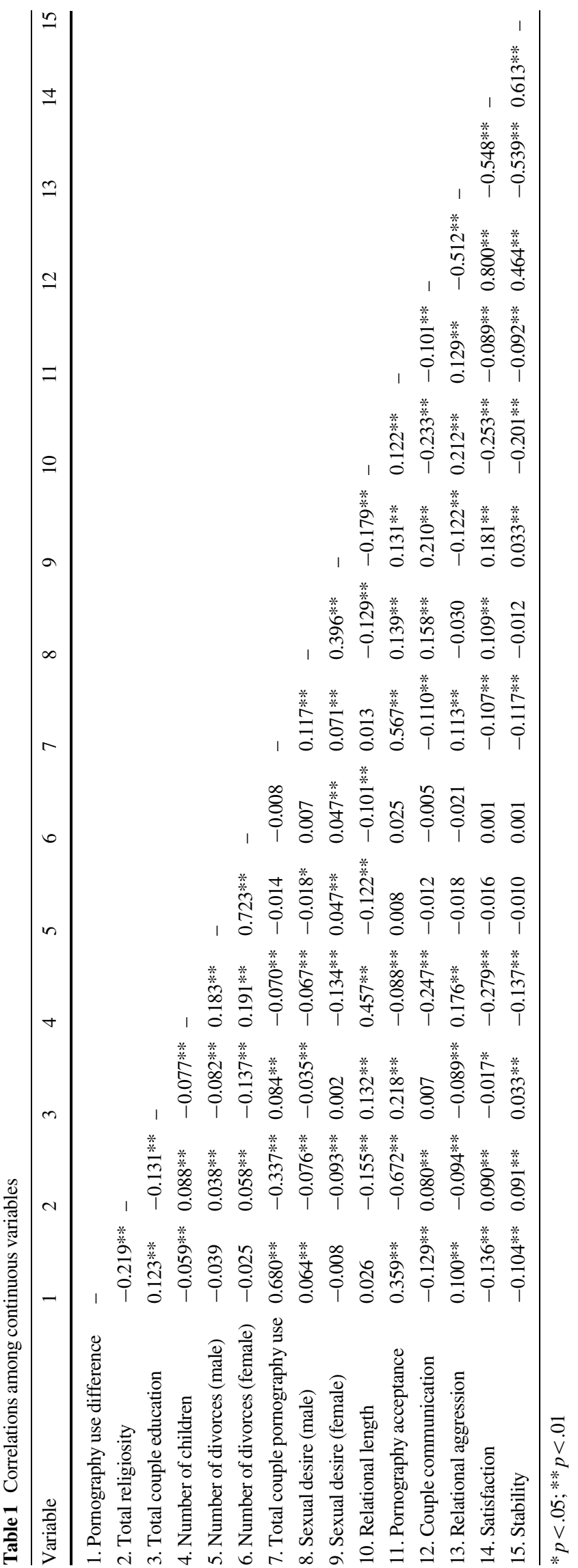


acceptance as separate indicators also did not change any significant results related to couple pornography differences.

For all four outcomes at Step 1, pornography use differences were significantly associated with each dependent variable. Associations were in the expected directions with a greater difference in pornography use being associated with less positive communication, more relational aggression, less satisfaction, and less stability. Once controls were entered into the model at Step 2, pornography use differences between partners were still significantly associated with less positive communication $(\beta=$ $-0.16, t=-7.09, p<.001)$, more relational aggression $(\beta=$ $0.12, t=5.21, p<.001)$, less relationship satisfaction $(\beta=$ $-0.15, t=-6.70, p<.001)$, and less stability $(\beta=-0.11, t=$ $-4.76, p<.001)$. These results confirmed Hypothesis 1 .

Final model results (Step 3) are summarized in Table 2. More couple differences in individual pornography use were still associated with less satisfaction, more relational aggression, and less positive communication in relationships, even when controlling for total pornography use and the sexual desire of both partners. However, the association between pornography use differences and stability was no longer significant. Among controls, relational status (being married), total education, and relational length all appeared to be important predictors of relational outcomes with all associations in the expected directions. Sexual desire of both partners was also associated with positive relational dynamics and outcomes.
Interaction terms between male/female pornography acceptance and couple use differences were then added to the full regression models. Significant results were obtained for both male and female acceptance by use difference interactions for models predicting positive communication (male acceptance: $\beta=0.06, p=.039$; female acceptance: $\beta=0.04, p=.028$ ). Female acceptance by use difference interactions were also significant for the model predicting satisfaction $(\beta=0.05, p=.016)$ and relational aggression $(\beta=-0.06, p=.003)$. Simple slope analyses suggested that the nature of this effect was similar in all cases. For example, couple pornography use differences had a significant negative association with couple satisfaction at all levels for male acceptance $(-1 S D: \beta=-0.15, p<.001 ; \mathrm{M}$ : $\beta=-0.11, p<.001 ;+1 S D: \beta=-0.08, p=.002)$ and female acceptance $(-1 S D: \beta=-0.19, p<.001 ; \mathrm{M}: \beta=-0.14$, $p<.001 ;+1 S D: \beta=-0.09, p=.001)$, but the association was diminished when acceptance of either partner was high. This interaction is depicted graphically for satisfaction and female acceptance in Fig. 1. The effect for positive communication and relational aggression (female acceptance only in both cases) wasidentical with one exception. Athigh levels of female pornography acceptance, couple use differences no longer had a significant association with relational aggression. In summary, couple pornography use differences were generally associated with negative relational outcomes but the effects were weakened for satisfaction when male and female pornography

Table 2 Final hierarchical regression models predicting couple communication, relational aggression, relationship satisfaction and stability

\begin{tabular}{|c|c|c|c|c|c|c|c|c|}
\hline \multirow[t]{2}{*}{ Variables } & \multicolumn{2}{|c|}{ Couple communication } & \multicolumn{2}{|c|}{ Relational aggression } & \multicolumn{2}{|l|}{ Satisfaction } & \multicolumn{2}{|l|}{ Stability } \\
\hline & $\beta$ & SE & $\beta$ & SE & $\beta$ & SE & $\beta$ & SE \\
\hline Age difference ${ }^{\mathrm{a}}$ & $-0.051^{*}$ & 0.019 & 0.035 & 0.040 & -0.030 & 0.034 & -0.036 & 0.034 \\
\hline Any religious attendance difference & -0.033 & 0.019 & 0.033 & 0.039 & -0.034 & 0.033 & -0.035 & 0.033 \\
\hline Total couple religiosity & $0.069 * *$ & 0.004 & -0.037 & 0.008 & $0.064 *$ & 0.007 & 0.031 & 0.007 \\
\hline Racial difference & -0.020 & 0.022 & $0.048 *$ & 0.046 & -0.036 & 0.039 & $-0.083 * *$ & 0.039 \\
\hline Number of children & $-0.069^{*}$ & 0.013 & 0.039 & 0.027 & $-0.088^{* *}$ & 0.022 & -0.035 & 0.022 \\
\hline Number of divorces (male) & 0.007 & 0.024 & -0.003 & 0.049 & -0.027 & 0.041 & -0.022 & 0.042 \\
\hline Number of divorces (female) & 0.016 & 0.035 & -0.041 & 0.072 & 0.012 & 0.061 & -0.002 & 0.061 \\
\hline Relational length & $-0.168 * *$ & 0.007 & $0.161 * *$ & 0.014 & $-0.159 * *$ & 0.012 & $-0.228 * *$ & 0.012 \\
\hline \multicolumn{9}{|l|}{ Relationship status } \\
\hline Dating (reference) & - & - & - & - & - & - & - & - \\
\hline Cohabiting & 0.018 & 0.024 & $-0.076 * *$ & 0.049 & 0.019 & 0.041 & $-0.067 *$ & 0.042 \\
\hline Married & $0.199 * *$ & 0.029 & $-0.166^{* *}$ & 0.060 & $0.233^{* *}$ & 0.051 & -0.013 & 0.051 \\
\hline Total couple education & $0.070 * *$ & 0.003 & $-0.139 * *$ & 0.006 & $0.046^{*}$ & 0.005 & $0.107 * *$ & 0.005 \\
\hline Total couple pornography use & $-0.061 *$ & 0.008 & $0.066^{*}$ & 0.016 & -0.053 & 0.013 & $-0.108 * *$ & 0.013 \\
\hline Male sexual desire & $0.100 * *$ & 0.008 & -0.012 & 0.016 & $0.046^{*}$ & 0.014 & 0.007 & 0.014 \\
\hline Female sexual desire & $0.136^{* *}$ & 0.008 & $-0.080 * *$ & 0.017 & $0.149 * *$ & 0.014 & 0.046 & 0.014 \\
\hline Pornography use difference ${ }^{b}$ & $-0.116^{* *}$ & 0.010 & $0.075^{*}$ & 0.022 & $-0.109 * *$ & 0.018 & -0.041 & 0.018 \\
\hline
\end{tabular}

\footnotetext{
${ }^{a}$ Difference of at least 2 years

b Absolute value of difference

$* p<.05 ; * *<.01$
} 


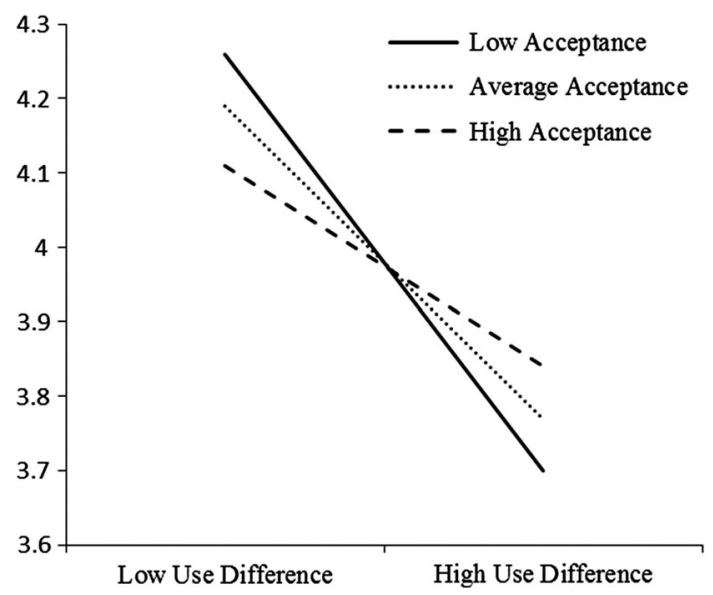

Fig. 1 Couple pornography use difference by female pornography acceptance interaction for model predicting couple satisfaction

acceptance was greater and weakened for communication and relational aggression when female acceptance was greater. This provided partial support for Hypothesis 2.

As our cross-sectional data did not allow for temporal sequencing of variables and given that associations between relationship well-being and pornography use are likely bidirectional, we also tested alternative models exploring if relationship wellbeing predicted total pornography use and use differences. Due to the highly correlated nature of our four relational well-being and dynamic measures, we focused on models utilizing overall relationship satisfaction as the key independent variable predicting pornography use. With the same controls as previous models, overall relationship satisfaction was significantly related to less differences in pornography use $(\beta=-0.16, t=$ $-6.49, p<.001)$ and less total pornography use among partners $(\beta=-0.13, t=-5.62, p<.001)$. In addition, secondary analyses were also conducted to examine if the gender of the partner engaging in pornography use impacted couple outcomes. To accomplish this, the pornography difference variable was removed from the model and male/female pornography use were entered in as separate variables. With these models, we found that male pornography use was associated with lower couple satisfaction $(\beta=-0.12, t=-5.33, p<.001)$, less stability $(\beta=-0.11$, $t=-4.75, p<.001)$, less positive communication $(\beta=-0.13$, $t=-5.83, p<.001)$, and more relational aggression $(\beta=0.10$, $t=4.25, p<.001)$. Female pornography use was not significantly associated with any couple assessments of well-being.

\section{Results of Mediation Model}

To explore how couple dynamic factors (couple communication, sexual desire, relational aggression) might mediate the relationship between pornography use differences and individual perceptions of satisfaction and stability and to more fully explore how gender may impact the previous couple-level results, actor- partner structural equation models were created and analyzed. Within these models, correlations between male and female scores were accounted for to control for inherent couple dependency. Analyses continued to control for age differences, total religiosity, racial differences, number of children, total pornography use, total education, and relationship length. Three models were analyzed (Figs. 2, 3, 4; only direct pathways shown) testing three different mediating factors in the prediction of relational satisfaction and stability. All mediating and dependent variables were regressed on all control variables in the model. These controls, error terms, and covariances were omitted from figures to focus on the primary results of interest.

Indirect pathways tested via the delta method provided evidence that several factors mediated the association between pornography use differences and male/female outcomes. Table 3 summarizes all total and specific indirect effects for each of the three models. For the communication model, all indirect pathways to male and female outcomes were significant, suggesting that male and female positive communication mediated the relationship between pornography differences and individual perception of couple outcomes. For the model including sexual desire, only indirect pathways through female sexual desire were significant. Female sexual desire mediated the relationship between pornography use differences and both male and female outcomes. Models suggested that greater pornography use differences were associated with less female sexual desire, which in turn was associated with a less reported male and female satisfaction and stability. For relational aggression, the opposite pattern was found. Only indirect pathways through male relational aggression were significant. In this case, a greater difference in pornography use was associated with more male relational aggression which was then associated with lower perceptions of relational outcomes for both partners. This provided partial support for Hypothesis 3 .

As data were cross-sectional, and to test if variable sequencing was ideal compared to alternative models, we also examined models in which relationship satisfaction and stability were allowed to predict couple dynamic variables which in turn were used to predict pornography use differences. These models included the same controls as the original models. In the case of all three models including sexual desire, effective communication, and relational aggression, the original models were significantly better fitting models than alternative models based on Chi square difference testing (results available from the first author upon request).

In terms of specific pathways and similar to previous regression results, more difference between partners in pornography use was associated with less male $(\beta=-0.19, p<.001)$ and less female $(\beta=-0.13, p<.001)$ positive communication (Fig. 1). However, divergent results were found for mediation models including sexual desire and relational aggression. More differences in pornography use were associated with less female ( $\beta=-0.13, p<.001)$ but not male $(\beta=-0.05, p=.12)$ sexual desire. More differences in pornography use were associated 


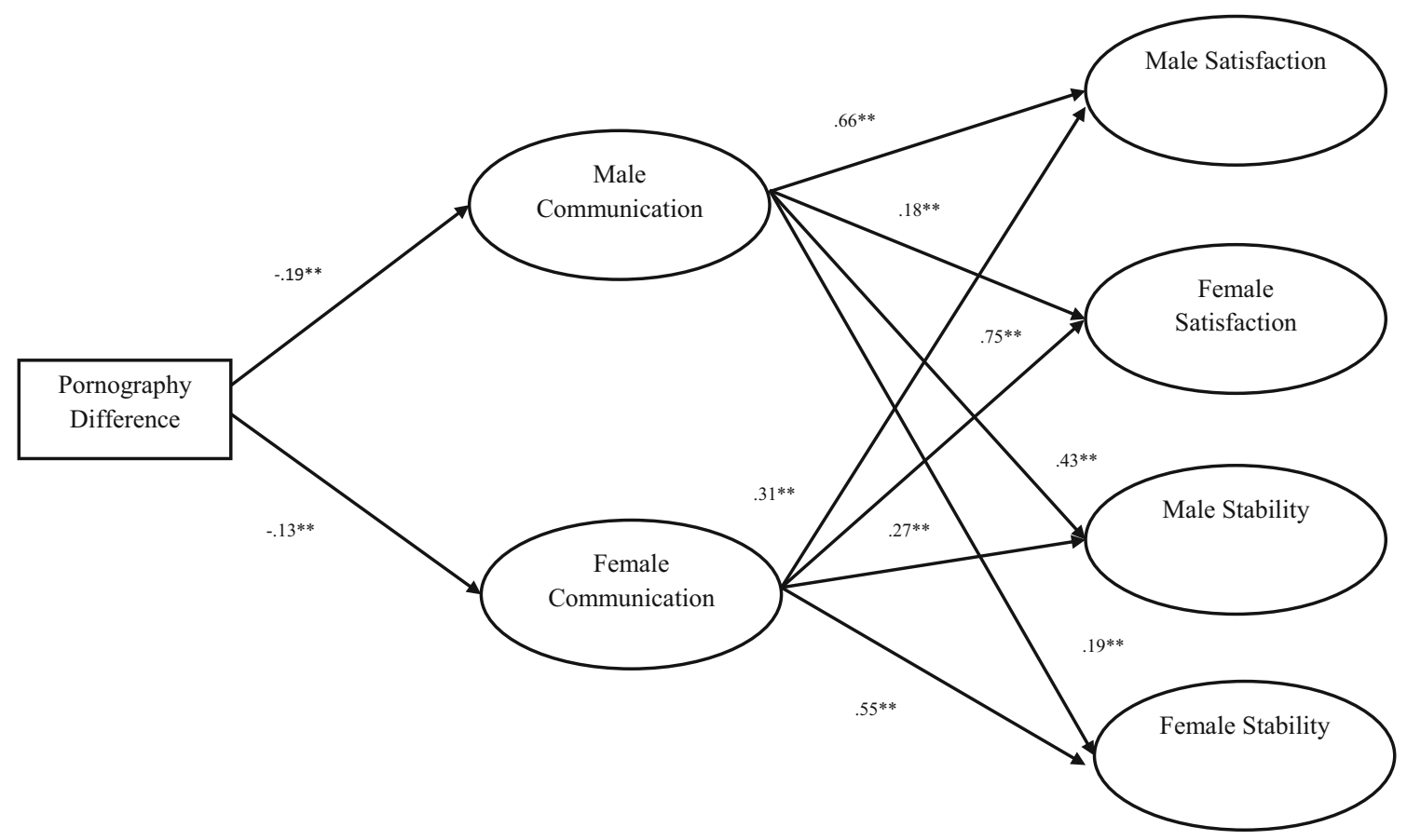

Fig. 2 Actor-partner mediation model for positive communication on the relationship between pornography use differences and relationship satisfaction and stability. Solid line represents significant pathways $(p<.01)$. Model fit statistics: $\chi^{2}(1241)=3415.17, \mathrm{RMSEA}=0.04, \mathrm{CFI}=0.94$,

with greater male $(\beta=0.11, p=.002)$ but not female aggression $(\beta=0.06, p=.16)$ suggesting that such mediating pathways differed by gender and provided support for Hypothesis 4.

In summary, mediation models suggested that less male and female positive communication, less female sexual desire, and more male relational aggression mediated the relationship between greater couple pornography use differences and lower perceptions of couple outcomes providing support for Hypotheses 3 and 4 .

\section{Discussion}

Results of the present study suggest that pornography use discrepancies may be associated with relationship processes and well-being for some couples. While numerous studies have suggested that individual pornography use (Bridges \& Morokoff, 2011; Carroll et al., 2008; Lambert et al., 2012; Yucel \& Gassanov, 2010) or couple pornography use (Bridges \& Morokoff, 2011; Daneback et al., 2009; Grov et al., 2011; Maddox et al., 2009) are associated with individual and relational outcomes, no study to date has explored how the discrepancy between couples in relation to their pornography use might uniquely be associated with relational outcomes. Across a series of analyses, greater pornography use differences were associated with more negative
$\mathrm{TLI}=0.93, \mathrm{SRMR}=0.04$. Model controlled for total pornography use, age differences, total religiosity, racial differences, relational length, total education and number of children. Only direct pathways between exogenous and endogenous latent variables shown

reports of couple well-being net of controls, confirming Hypothesis 1 . It is important to note that such associations were found even when controlling for a range of demographic factors and relational sexual patterns, couple overall pornography use, and sexual desire. While the effect after controls was generally small, accounting for only 1 or $2 \%$ additional variance in the outcome variables, there appears to be sufficient evidence to suggest that connections between pornography use differences and outcomes exists and that such associations are unique contributors beyond baseline pornography use. Given that virtually all (95\%) pornography differences involved a male partner using more than a female partner and male, but not female, pornography use was found to have significant associations with negative couple wellbeing, such findings may represent unique gendered patterns as well and speak to the impact on relationships of male pornography use in the absence of female use.

Why would pornography use differences be associated with more negative relationship outcomes? The reason is likely similar to what other scholars have suggested in regard to differences in other areas of couples' lives that may create potential conflict areas. Like differences in age or religion (Heaton, 2002; Teachman, 2002), differences in pornography use patterns may be linked to underlying paradigm and value differences. In the case of pornography use, such use patterns may be associated with underlying sexual ethics (Reiss, 1960; Sprecher \& McKinney, 1993), suggesting that partners may fundamentally disagree on the nature, purpose, and function of sexual intimacy within 


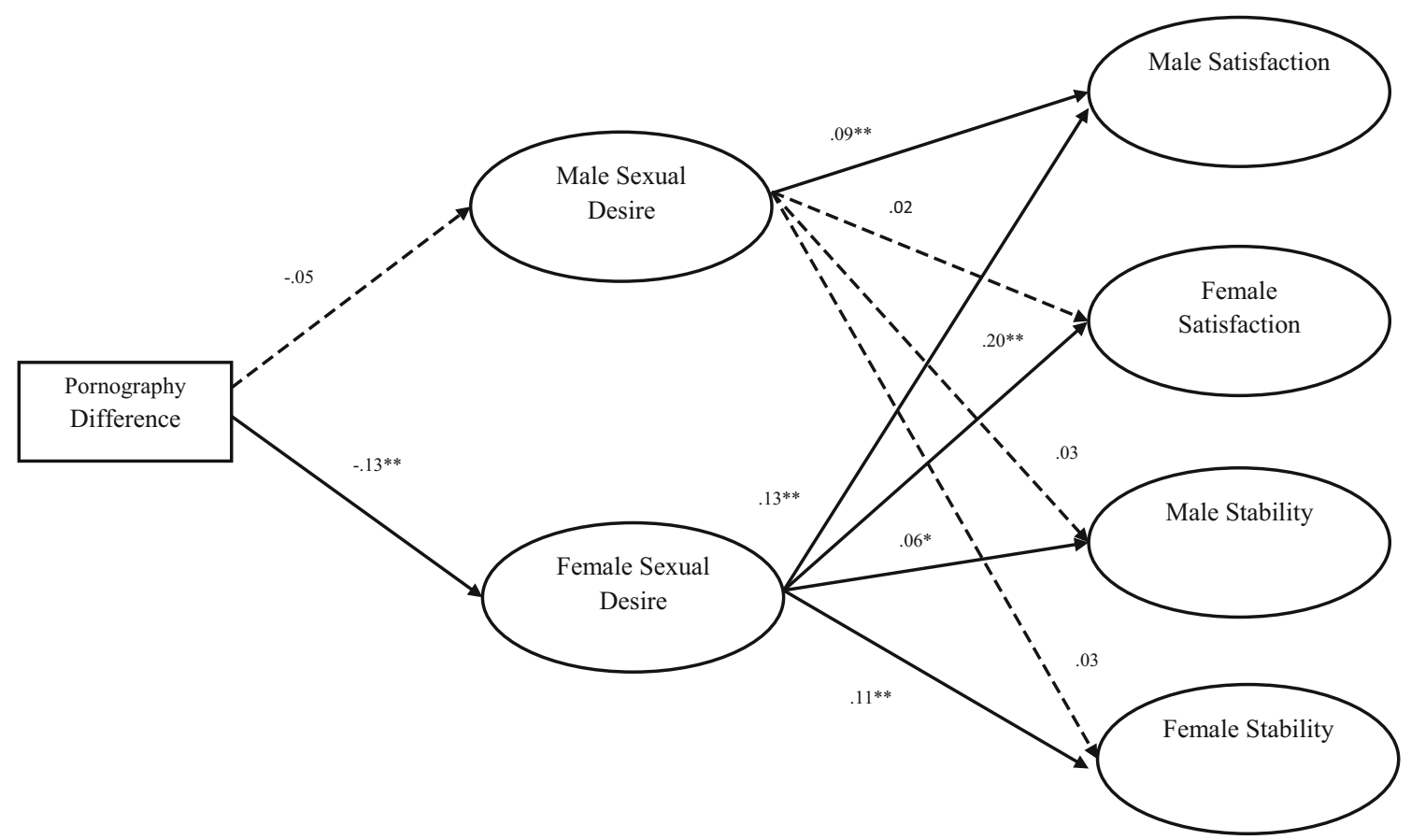

Fig. 3 Actor-partner mediation model for sexual desire on the relationship between pornography use differences and relationship satisfaction and stability. Solid line represents significant pathways $(p<.01)$. Model fit statistics: $\chi^{2}(191)=815.47, \mathrm{RMSEA}=0.04, \mathrm{CFI}=0.97, \mathrm{TLI}=0.95$,

their relationship. That many of these associations were moderated by acceptance levels (confirming Hypothesis 2) further suggests that underlying values and beliefs about pornography are important factors when considering the correlates of pornography. Complementing previous research (Nelson et al., 2010), when acceptance of pornography was high, particularly when such acceptance was from female partners, associations between pornography use differences and negative outcomes was greatly diminished. This may provide some limited evidence that female acceptance serves as a buffer to the potential negative impacts of higher male pornography use (Olmstead et al., 2013), which is the cause of most reported pornography differences within the sample.

Mediation analyses offered further insight to the connections between pornography use differences and outcomes. Direct associations between pornography use differences and relationship well-being were generally weak. While pornography use differences appear related to relationship outcomes, such associations were only one small part of what makes relationships generally healthy or unhealthy. However, indirect effects through possible mediating factors of couple dynamics suggest stronger effects, with full models accounting for between $10 \%$ (sexual desire model) and $77 \%$ (communication model) of the variance in male and female outcomes. Results suggested that greater differences between partners in pornography use were associated with greater male relational aggression, lower female sexual desire, and less positive communication for both partners. Pornography differ-
SRMR $=0.03$. Model controlled for total pornography use, age differences, total religiosity, racial differences, relational length, total education and number of children. Only direct pathways between exogenous and endogenous latent variables shown

ences in these mediation models accounted for between 6 and $10 \%$ of the variance in sexual desire, effective communication, and relational aggression. These relational process factors were then associated with lower reported satisfaction and stability for both partners. While pornography use differences may be associated with only small fluctuations in couple dynamics, such small adjustments may over time, and if not addressed by romantic partners, lead tolarger shifts in relationshipoutcomes. While dataexamined here were cross-sectional and thus unable to speak to the casual directionality of such associations, they do suggest an interesting relational pattern to be explored in future studies.

Since most pornography use differences involved a male using pornography more than his female partner, it may be that male pornography users are becoming relationally aggressive in their relationship, perhaps being dissatisfied with their partner as the frequent viewing of pornography changes their expectations and perception of their partner (see Bridges \& Morokoff, 2011; Grov et al., 2011). Some studies have shown limited connections between viewing violent forms of pornography and more propensity toward sexual aggression among some men (Malamuth, Hald, \& Koss, 2012). Perhaps some male pornography users may also be more inclined to use relational aggression in their relationship, mimicking the aggressive male behavior they view in some forms of pornography. This increased aggression may then lower his female partner's sexual desire as females are prone to desire fluctuations based on the relational environment of the partnership. Or perhaps the direction is reversed, where the 


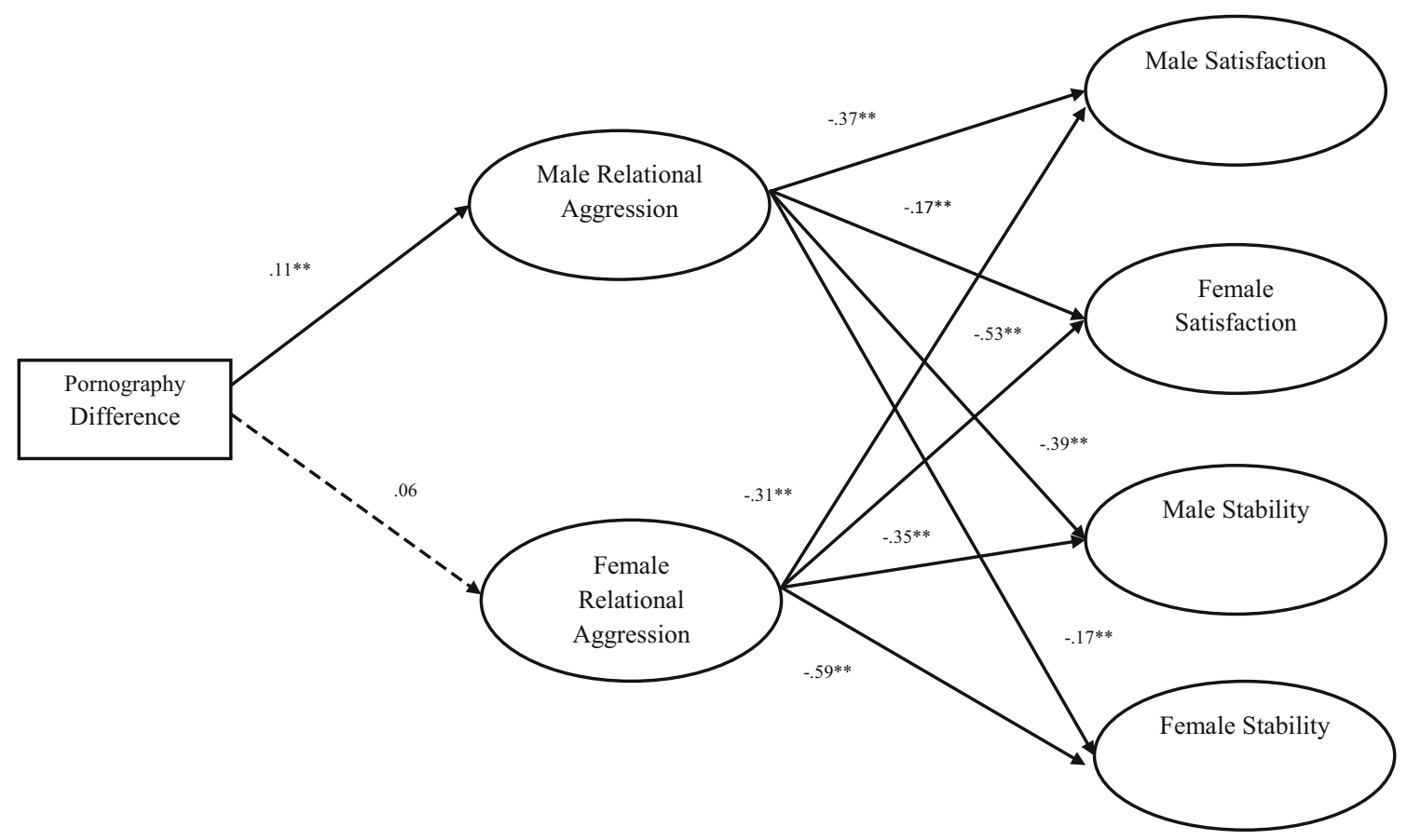

Fig. 4 Actor-partner mediation model for relational aggression on the relationship between pornography use differences and relationship satisfaction and stability. Solid line represents significant pathways $(p<.01)$. Model fit statistics: $\chi^{2}(479)=1839.83$, RMSEA $=0.04, \mathrm{CFI}=0.95$,

knowledge of a male partner's pornography use decreases his female partner's desire for intercourse which leads male partners to turn to relational aggression tactics in their interactions. As the general environment of the relationship is prone to conflict due to these factors, the positive communication utilized by both partners may also diminish. Again, such directional hypotheses are at this point merely speculative, but do offer important possibilities for future research studies to consider. Regardless of their directionality, it seems that pornography use differences and couple dynamics are linked in important ways and that such links may have ramifications to overall couple stability and well-being.

It should be noted that indirect effects through sexual desire were generally weaker than indirect effects through both communication and relational aggression. This was largely due to the weaker direct association between sexual desire and relationship well-being indicators. This corresponds to previous research which suggests that although high quality communication and the absence of relational aggression may be universal markers of healthy relationships, a desire for sexual frequency may naturally ebb and flow due to natural occurrences and disruptions to sexual practices within a relationship such as pregnancy or other chronic health conditions (von Sydow, 1999). Put another way, a lack of current sexual desire for one's partner may not necessarily be a marker of a low quality relationship in some circumstances. Thus, caution should be employed before suggesting that the links between pornography discrepancies and low sexual desire are clear markers of unhealthy relationships.
$\mathrm{TLI}=0.94, \mathrm{SRMR}=0.04$. Model controlled for total pornography use, age differences, total religiosity, racial differences, relational length, total education and number of children. Only direct pathways between exogenous and endogenous latent variables shown

\section{Practical Implications}

Results of the present study also suggest some practical implications. From a practical standpoint, attachment theory offers important insights. Scholars and therapists have suggested that attachment theory provides a useful theoretical lens for explaining the specific mechanisms by which pornography influences couple relationships and for explaining the possible negative effects to couple process, particularly when partners have differing views of pornography (Zitzman \& Butler, 2009). Within the attachment perspective, relationship satisfaction is viewed as a result of partners developing a secure attachment in their pair-bond, where each partner trusts that the other will be physically, emotionally, and psychologically responsive to his or her needs (Cassidy \& Shaver, 1999). These emotional perceptions and behavioral patterns, which partners commonly describe as trust, are the basis for secure attachment in the adult pair-bond relationship (Hazan \& Zeifman, 1999). Behavior that disrupts or erodes secure attachment, or diminishes a sense of trust, will then have a significant negative impact on couple communication, intimacy, and satisfaction.

In consequence of such theorizing on the significance of secure attachment, discrepancies in pornography scripts and use may influence the non-using or low-use partners', typically the women's, sense of trustworthiness and security in the relationship (Butler \& Seedall, 2006; Leedes, 1999). Zitzman and Butler (2009) explain, "Pornography scripts expectations and behavior 
Table 3 Summary of standardized total and indirect effects

\begin{tabular}{|c|c|c|}
\hline Variable & $\beta$ & SE \\
\hline \multicolumn{3}{|l|}{ Communication model } \\
\hline Pornography difference $\rightarrow$ male satisfaction (total indirect) & $-0.16^{* *}$ & 0.032 \\
\hline Pornography difference $\rightarrow$ M communication $\rightarrow$ M satisfaction & $-0.13^{* *}$ & 0.026 \\
\hline Pornography difference $\rightarrow \mathrm{F}$ communication $\rightarrow \mathrm{M}$ satisfaction & $-0.04 * *$ & 0.012 \\
\hline Pornography difference $\rightarrow$ female satisfaction (total indirect) & $-0.13 * *$ & 0.032 \\
\hline Pornography difference $\rightarrow$ M communication $\rightarrow$ F satisfaction & $-0.03 * *$ & 0.008 \\
\hline Pornography difference $\rightarrow \mathrm{F}$ communication $\rightarrow \mathrm{F}$ satisfaction & $-0.10^{* *}$ & 0.029 \\
\hline Pornography difference $\rightarrow$ male stability (total indirect) & $-0.12 * *$ & 0.023 \\
\hline Pornography difference $\rightarrow$ M communication $\rightarrow$ M stability & $-0.08 * *$ & 0.017 \\
\hline Pornography difference $\rightarrow$ M communication $\rightarrow$ F stability & $-0.04 * *$ & 0.011 \\
\hline Pornography difference $\rightarrow$ female stability (total indirect) & $-0.11 * *$ & 0.025 \\
\hline Pornography difference $\rightarrow \mathrm{M}$ communication $\rightarrow \mathrm{M}$ stability & $-0.04 * *$ & 0.009 \\
\hline Pornography difference $\rightarrow \mathrm{F}$ communication $\rightarrow \mathrm{F}$ stability & $-0.07 * *$ & 0.021 \\
\hline \multicolumn{3}{|l|}{ Sexual desire model } \\
\hline Pornography difference $\rightarrow$ male satisfaction (total indirect) & $-0.02 * *$ & 0.006 \\
\hline Pornography difference $\rightarrow$ M sexual desire $\rightarrow$ M satisfaction & -0.005 & 0.003 \\
\hline Pornography difference $\rightarrow \mathrm{F}$ sexual desire $\rightarrow$ M satisfaction & $-0.02 * *$ & 0.005 \\
\hline Pornography difference $\rightarrow$ female satisfaction (total indirect) & $-0.03 * *$ & 0.007 \\
\hline Pornography difference $\rightarrow$ M sexual desire $\rightarrow$ F satisfaction & -0.001 & 0.001 \\
\hline Pornography difference $\rightarrow$ F sexual desire $\rightarrow$ F satisfaction & $-0.03^{* *}$ & 0.007 \\
\hline Pornography difference $\rightarrow$ male stability (total indirect) & $-0.009 *$ & 0.004 \\
\hline Pornography difference $\rightarrow$ M sexual desire $\rightarrow$ M stability & -0.002 & 0.002 \\
\hline Pornography difference $\rightarrow$ M sexual desire $\rightarrow$ F stability & $-0.007^{*}$ & 0.004 \\
\hline Pornography difference $\rightarrow$ female stability (total indirect) & $-0.02 * *$ & 0.005 \\
\hline Pornography difference $\rightarrow$ M sexual desire $\rightarrow$ M stability & -0.001 & 0.002 \\
\hline Pornography difference $\rightarrow$ F sexual desire $\rightarrow$ F stability & $-0.01 * *$ & 0.005 \\
\hline \multicolumn{3}{|l|}{ Relational aggression model } \\
\hline Pornography difference $\rightarrow$ male satisfaction (total indirect) & $-0.06^{* *}$ & 0.020 \\
\hline Pornography difference $\rightarrow$ M relational aggression $\rightarrow$ M satisfaction & $-0.04 * *$ & 0.013 \\
\hline Pornography difference $\rightarrow$ F relational aggression $\rightarrow$ M satisfaction & -0.02 & 0.011 \\
\hline Pornography difference $\rightarrow$ female satisfaction (total indirect) & $-0.05^{*}$ & 0.022 \\
\hline Pornography difference $\rightarrow$ M relational aggression $\rightarrow$ F satisfaction & $-0.02 * *$ & 0.007 \\
\hline Pornography difference $\rightarrow$ F relational aggression $\rightarrow$ F satisfaction & -0.03 & 0.019 \\
\hline Pornography difference $\rightarrow$ male stability (total indirect) & $-0.06^{* *}$ & 0.021 \\
\hline Pornography difference $\rightarrow$ M relational aggression $\rightarrow$ M stability & $-0.04 * *$ & 0.014 \\
\hline Pornography difference $\rightarrow$ M relational aggression $\rightarrow$ F stability & -0.02 & 0.013 \\
\hline Pornography difference $\rightarrow$ female stability (total indirect) & $-0.05^{*}$ & 0.024 \\
\hline Pornography difference $\rightarrow$ M relational aggression $\rightarrow$ M stability & $-0.02 * *$ & 0.007 \\
\hline Pornography difference $\rightarrow$ F relational aggression $\rightarrow$ F stability & -0.04 & 0.021 \\
\hline
\end{tabular}

Pornography difference measured as the absolute value of male use minus female use

$* p<.05 ; * * p<.01$

that place it on a collision course with the requisite dynamics for secure attachment and authentic intimacy in the pair-bond relationship...the detached, objectifying, exploitive sexuality of pornography directly impacts attachment trust, eroding any safe expectation of one's partner being faithfully for the other" ( $p$. 214). If a woman sees pornography as an untrustworthy act that turns her partner's attraction toward others or as an indicator that he approaches sex from a self-centered, rather than other-centered orientation, her sense of security will diminish in the relationship. However, attachment scholars have emphasized that the "structure of security" in pair-bond relationships may be somewhat subjective, and can vary from relationship to relationship 
(Cassidy \& Shaver, 1999). As the current study suggests, partner discrepancies in pornography use will likely influence whether or not pornography is seen as a violation of relationship trust, thus influencing overall relationship satisfaction. Thus, clinicians working with couples who present discrepancies in pornography use may wish to explore trust and attachment issues to see if such discrepancies have altered attachment bonds between partners.

\section{Limitations and Future Directions}

This study had several limitations that should be considered before generalizing results. First, as mentioned previously, data were cross-sectional and care should be taken to not imply causality from the associations found. Increased pornography use may result from varying relational processes or outcomes and longitudinal data are needed to sort out these complex relationships. While some scholars have argued that pornography use may cause negative relational dynamics (Poulsen et al., 2013), directionality of such relationships cannot be inferred. While alternative mediation models were tested and the model predicting relationship well-being from pornography difference proved to be the better fitting model, alterative models were still significant. In addition, regression models predicting pornography use differences from relationship well-being indicators were significant and in the same direction as associations reported. Generally such relationships are likely reciprocal in nature.

Future studies should also consider how the type and context of pornography use may change the results seen here. The dataset utilized only included items assessing general pornography use. The inclusion of more detailed measurement that can assess the type of pornography used (video, internet, etc.), the amount of time it was utilized, and the content of the pornography would be an important step for future research. Furthermore, even the term pornography itself may be interpreted differently by individuals of differing cultural and religious backgrounds. While we found general associations between relational outcomes and pornography use differences, perhaps differences in the content or way in which pornography is utilized are also salient factors in couple relationships. Furthermore, while the present study was focused on continuous pornography use differences among couples, future research should continue to explore discrete differences in couple types. For example, a more detailed analysis of couples where one partner uses pornography and one partner does not would provide needed content and depth to our understanding of pornography use differences among couples. Such studies should also focus more on the unique gender aspect of use by examining if male or female partner use difference change results reported here. The sample for the current project was also not representative of all couples. Couples who take the RELATE assessment tend to have better quality and more stable relationships and tend to be more educated than would be expected in a truly representative dataset thus care should be taken before generalizing these findings to all romantic couples.

Despite these limitations, the present study provided concrete evidence that pornography use differences within couple relationships are a meaningful part of relational well-being. Although the overall effect of pornography on relational well-being may be small, such an effect should not be overlooked due to its possible clinical and practical implications. That large pornography use discrepancies between partners may be associated with a range of negative outcomes has implications for both relational scholars seeking to understand how pornography use impacts couple process as well as clinicians hoping to help intervene with couples seeking treatment for pornography related conflict. Scholars should continue to explore the nuances of pornography use patterns and seek to understand how within couple patterns of pornography use may provide important insights into the correlates of such behavior.

\section{References}

Aiken, L. S., \& West, S. G. (1991). Multiple regression: Testing and interpreting interactions. Newbury Park, CA: Sage.

Booth, A., Johnson, D., \& Edwards, J. N. (1983). Measuring marital instability. Journal of Marriage and the Family, 45, 387-394.

Bridges, A. J., Bergner, R. M., \& Hesson-McInnis, M. (2003). Romantic partners' use of pornography: Its significance for women. Journal of Sex and Marital Therapy, 29, 1-14.

Bridges, A. J., \& Morokoff, P. J. (2011). Sexual media use and relational satisfaction in heterosexual couples. Personal Relationships, 18, 562 585.

Busby, D. M., Holman, T. B., \& Niehuis, S. (2009). The association between partner enhancement and self-enhancement and relationship quality outcomes. Journal of Marriage and Family, 71, 449-464.

Busby, D. M., Holman, T. B., \& Taniguchi, N. (2001). RELATE: Relationship evaluation of the individual, family, cultural, and couple contexts. Family Relations, 50, 308-316.

Busby, D. M., Ivey, D. C., Harris, S. M., \& Ates, C. (2007). Self-directed, therapist-directed, and assessment-based interventions for premarital couples. Family Relations, 56, 279-290.

Butler, M. H., \& Seedall, R. B. (2006). The attachment relationship in recovery from addiction. Part 1: Relationship mediation. Sexual Addiction \& Compulsivity, 13, 289-315.

Carroll, J. S., Nelson, D. A., Yorgason, J. B., Harper, J. M., Ashton, R., \& Jensen, A. C. (2010). Relational aggression in marriage. Aggressive Behavior, 36, 315-329.

Carroll, J. S., Padilla-Walker, L. M., Nelson, L. J., Olson, C. D., Barry, C., \& Madsen, S. D. (2008). Generation XXX: Pornography acceptance and use among emerging adults. Journal of Adolescent Research, 23, 630.

Cassidy, J., \& Shaver, P. R.(Eds.).(1999). Handbook of attachment: Theory, research, and clinical applications. New York: Guilford Press.

Cook, W. L., \& Kenny, D. A. (2005). The actor-partner interdependence model: A model of bidirectional effects in developmental studies. International Journal of Behavioral Development, 29, 101-109.

Cooper, A., Galbreath, N., \& Becker, M. A. (2004). Sex on the internet: Further our understanding of men with online sexual problems. Psychology of Addictive Behaviors, 18, 223-230.

Daneback, K., Træen, B., \& Månsson, S. (2009). Use of pornography in a random sample of Norwegian heterosexual couples. Archives of Sexual Behavior, 38, 746-753.

Dariotis, J. K., Sifakis, F., Pleck, J. H., Astone, N. M., \& Sonenstein, F. L. (2011). Racial and ethnic disparities in sexual risk behaviors and STDs 
during young men's transition to adulthood. Perspectives on Sexual and Reproductive Health, 43, 51-59.

Gagnon, J. H., \& Simon, W. (1973). Youth, sex, and the future. In D. D. Gottlieb (Ed.), Youth in contemporary society (pp. 211-257). Oxford: Sage.

Gottman, J. M., Coan, J., Carrere, S., \& Swanson, C. (1998). Predicting marital happiness and stability from newlywed interactions. Journal of Marriage and the Family, 60, 5-22.

Grov, C., Gillespie, B., Royce, T., \& Lever, J. (2011). Perceived consequences of casual online sexual activities on heterosexual relationships: A U. S. online survey. Archives of Sexual Behavior, 40, 429-439.

Hazan, C., \& Zeifman, D. (1999). Pair bonds as attachments: Evaluating the evidence. In J.Cassidy \& P. R. Shaver(Eds.), Handbook of attachment: Theory, research, and clinical applications (pp. 336-354). New York: Guilford Press.

Heaton, T. B. (2002). Factors contributing to increasing marital stability in the United States. Journal of Family Issues, 23, 392-409.

Lambert, N. M., Negash, S., Stillman, T. F., Olmstead, S. B., \& Fincham, F. D. (2012). A love that doesn't last: Pornography consumption and weakened commitment to one's romantic partner. Journal of Social and Clinical Psychology, 31, 410-438.

Leedes, R. (1999). Theory and praxis: A heuristic for describing, evaluating, and intervening on sexual desire disorders when sexual expression interferes with humanistic expression. Sexual Addiction and Compulsivity, 6, 289-310.

Lofgren-Mårtenson, L., \& Månsson, S. (2010). Lust, love, and life: A qualitative study of Swedish adolescents' perceptions and experiences with pornography. Journal of Sex Research, 47, 568-579.

Luo, S., Chen, H., Yue, G., Zhang, G., Zhaoyang, R., \& Xu, D. (2008). Predicting marital satisfaction from self, partner, and couple characteristics: Is it me, you, or us? Journal of Personality, 76, 1231-1265.

Maddox, A. M., Rhoades, G. K., \& Markman, H. J. (2009). Viewing sexually-explicit materials alone or together: Associations with relationship quality. Archives of Sexual Behavior, 40, 441-448.

Malamuth, N. M., Hald, G. M., \& Koss, M. (2012). Pornography, individual differences in risk and men's acceptance of violence against women in a representative sample. Sex Roles, 66, 427-439.

Nelson, L. J., Padilla-Walker, L. M., \& Carroll, J. S. (2010). "I believe it is wrong but I still do it": A comparison of religious young men who do versus do not use pornography. Psychology of Religion and Spirituality, 2, 136-147.

Olmstead, S. B., Negash, S., Pasley, K., \& Fincham, F. D. (2013). Emerging adults' expectations for pornography use in the context of future committed romantic relationships: A qualitative study. Archives of Sexual Behavior, 42, 625-635.

Owen, J. J., Rhoades, G. K., Stanley, S. M., \& Fincham, F. D. (2010) "Hooking up" among college students: Demographic and psychosocial correlates. Archives of Sexual Behavior, 39, 653-663.
Poulsen, F. O., Busby, D. M., \& Galovan, A. M. (2013). Pornography use: Who uses it and how it is associated with couple outcomes. Journal of Sex Research, 50, 72-83.

Reiss, I. L. (1960). Premarital sexual standards in America. New York: Free Press.

Schneider, J. P. (2000). Effects of cybersex addiction on the family: Results of a survey. Sexual Addiction \& Compulsivity, 7, 31-58.

Simmons, C. A., Lehmann, P., \& Collier-Tenison, S. (2008). Linking male use of the sex industry to controlling behaviors in violent relationships. Violence Against Women, 14, 406-417.

Sinkovic, M., Stulhofer, A., \& Bozic, J. (2012). Revisiting the association between pornography use and risky sexual behaviors: The role of early exposure to pornography and sexual sensation seeking. Journal of Sex Research, 50, 633-641.

Sprecher, S., \& McKinney, K. (1993). Sexuality. Thousand Oaks, CA: Sage Publications.

Stack, S., Wasserman, I., \& Kern, R. (2004). Adult social bonds and use of internet pornography. Social Science Quarterly, 85, 75-88.

Teachman, J. D. (2002). Stability across cohorts in divorce risk factors. Demography, 39, 331-351.

Traeen, B., Spitznogle, K., \& Beverfjord, A. (2004). Attitudes and use of pornography in the Norwegian population 2002. Journal of Sex Research, 41, 193-200.

Twohig, M. P., Crosby, J. M., \& Cox, J. M. (2009). Viewing Internet pornography: For whom is it problematic, how, and why? Sexual Addiction \& Compulsivity, 16, 253-266.

von Sydow, K. (1999). Sexuality during pregnancy and after childbirth: A meta-content analysis of 59 studies. Journal of Psychosomatic Research, 47, 27-49.

Weinberg, M. S., Williams, C. J., Kleiner, S., \& Irizarry, Y. (2010). Pornography, normalization, and empowerment. Archives of Sexual Behavior, 39, 1389-1401.

Wetterneck, C. T., Burgess, A. J., Short, M. B., Smith, A. H., \& Cervantes, M. E. (2012). The role of sexual compulsivity, impulsivity, and experiential avoidance in Internet pornography use. Psychological Record, 62, 3-18.

Willoughby, B. J., Farero, A., \& Busby, D. M. (2014). Exploring the effects of sexual desire discrepancy among married couples. Archives of Sexual Behavior, 43, 551-562.

Yucel, D., \& Gassanov, M. A. (2010). Exploring actor and partner correlates of sexual satisfaction among married couples. Social Science Research, $39,725-738$

Zitzman, S. T., \& Butler, M. H. (2009). Wives' experience of husbands' pornography use and concomitant deception as an attachment threat in the adult pair-bond relationship. Sexual Addiction \& Compulsivity, 16, 210-240. 